1

Original article

\title{
Premenopausal cardiovascular disease and age at natural menopause: A pooled analysis of over 170,000 women
}

Dongshan Zhu ${ }^{1}$, Hsin-Fang Chung ${ }^{1}$, Nirmala Pandeya ${ }^{1,2}$, Annette J. Dobson ${ }^{1}$, Rebecca $\mathrm{Hardy}^{3}$, Diana Kuh ${ }^{3}$, Eric J. Brunner ${ }^{4}$, Fiona Bruinsma ${ }^{5}$, Graham G. Giles ${ }^{5,6}$,

Panayotes Demakakos ${ }^{7}$, Jung Su Lee ${ }^{8}$, Hideki Mizunuma ${ }^{9}$, Kunihiko Hayashi ${ }^{10}$, HansOlov Adami ${ }^{11,12}$, Elisabete Weiderpass ${ }^{11,13,14,15}$, Gita D. Mishra ${ }^{1}$

${ }^{1}$ The University of Queensland, School of Public Health, Brisbane, Queensland, Australia

${ }^{2}$ Department of Population Health, QIMR Berghofer Medical Research Institute, Brisbane, Queensland, Australia

${ }^{3}$ Medical Research Council Unit for Lifelong Health and Ageing at UCL, London, UK

${ }^{4}$ Department of Epidemiology and Public Health, University College London, London, UK

${ }^{5}$ Cancer Epidemiology and Intelligence Division, Cancer Council Victoria, Melbourne, Victoria, 3004, Australia

${ }^{6}$ Centre for Epidemiology and Biostatistics, Melbourne School of Population and Global Health, The University of Melbourne, Melbourne, Victoria 3010, Australia

${ }^{7}$ Department of Epidemiology and Public Health, University College London, London, UK

${ }^{8}$ Department of Public Health, Graduate School of Medicine, The University of Tokyo, Tokyo 113-8654, Japan

${ }^{9}$ Fukushima Medical Center for Children and Women, Fukushima Medical University, Fukushima, 960-1295, Japan 
$27{ }^{10}$ School of Health Sciences, Gunma University, Maebashi City, Gunma 371-0044, 28 Japan

$29{ }^{11}$ Department of Medical Epidemiology and Biostatistics, Karolinska Institutet, 30 Stockholm, Sweden

$31{ }^{12}$ Clinical Effectiveness Research Group, Institute of Health and Society, University 32 of Oslo, Oslo, Norway

$33{ }^{13}$ Genetic Epidemiology Group, Folkhälsan Research Center, Faculty of Medicine, 34 University of Helsinki, Helsinki, FI-00290, Finland

$35{ }^{14}$ Department of Community Medicine, Faculty of Health Sciences, University of 36 Tromsø, The Arctic University of Norway, Tromsø, 9019, Norway

$37{ }^{15}$ Department of Research, Cancer Registry of Norway, Institute of Population-Based 38 Cancer Research, Oslo, 0304, Norway

40 Corresponding author:

41 Dongshan Zhu, MD

42288 Herston Road (corner of Herston Rd and Wyndham St)

43 School of Public Health, University of Queensland,

44 Brisbane, Queensland 4006, Australia

45 TEL: +61-7-3365-5224, FAX: +61-7-3365-5540

46 Email: dongshan.zhu@uq.net.au 


\section{ABSTRACT}

\section{Background}

Early menopause is associated with an increased risk of subsequent cardiovascular disease (CVD). Few studies have investigated the converse. We examined whether premenopausal CVD events are associated with early age at menopause.

\section{Methods}

We pooled the individual data of 177131 women from nine studies. We used multinomial logistic regression models to estimate multivariable relative risk ratios (RRR) and 95\% confidence intervals (CI) for the associations between age at onset of premenopausal CVD events -including coronary heart disease (CHD) and stroke - and age at natural menopause.

\section{Results}

Altogether $1561(0.9 \%)$ premenopausal participants reported CVD events (including $1130 \mathrm{CHD}$ and 469 stroke) at a mean age of 41.3 years. Compared with women without any premenopausal CVD events, women who experienced a first CVD event before age 35 years had a 2 -fold risk of menopause before age 45 years (early menopause); adjusted RRR $(95 \% \mathrm{CI})$ of $1.92(1.17,3.14)$ for any CVD, $1.86(1.01$, 3.43) for CHD and $2.17(1.43,3.30)$ for stroke. Women who experienced a first premenopausal CVD event after age 40 years underwent a natural menopause at the expected age (around 51 years). These associations were robust to adjustment for smoking status, BMI, educational level, race/ethnicity, age at menarche, parity, hypertension and family history of CVD.

\section{Conclusions}


70 For premenopausal women, a first CVD event before age 35 years is associated with a

71 doubling of the risk of an early menopause, while a first CVD event occurred after 35

72 years indicates a normal menopause at around 51 years. Shared genetic and

73 environmental factors (such as smoking), as well as compromised vasculature

74 following CVD events, may contribute to this outcome.

75 Keywords Premenopausal $\cdot$ Cardiovascular disease $\cdot$ Age at menopause $\cdot$ Pooled

76 analysis

77 


\section{INTRODUCTION}

Menopause, defined as cessation of menstrual bleeding for at least 12 months, marks the end stage of reproductive ageing [1]. Average age at menopause is 51.4 years in high-income countries $[2,3]$. Early menopause, i.e., occurring before the age of 45 years, affects approximately 5\% of women [4] and entails increased risk of non-fatal and fatal cardiovascular disease (CVD) and of all-cause mortality [5-9].

The reduction in circulating estrogen concentration during the menopausal transition is accompanied by unfavorable changes to CVD risk factors such as body fat distribution, blood pressure, and blood lipid levels [10-16] and, is considered, thereby, to trigger vascular ageing [17]. However, this model has been challenged by the finding of no CVD risk reduction, and possibly even an increased risk [18], following exogenous menopausal hormone therapy (MHT). This inconsistency led us to consider the converse model, i.e., that cardiovascular damage itself is a driving factor in the process of ovarian ageing. This model is indirectly supported by two studies. In the Framingham Heart Study, Kok et al. found premenopausal cardiovascular risk factors were associated with younger age at menopause $[19,20]$. Another study reported women who experienced early natural menopause were more often smokers, had diabetes, and had higher average body mass index (BMI) [21]. If premenopausal CVD risk factors are associated with women's age at natural menopause, the question that follows is whether premenopausal CVD events might also be linked to reproductive ageing and early age at natural menopause. To date, no study has examined this question directly. As premenopausal CVD events are rare, a study with a large sample size is required to answer this question with adequate precision. 
101 To this end we pooled participant-level data from multiple studies in the International

102 collaboration for a Life course Approach to reproductive health and Chronic disease

103 Events (InterLACE) [22, 23]. We examined the association between premenopausal

104 CVD events and age at natural menopause with detailed adjustment for confounding

105 by race/ethnicity, education, BMI, smoking, hypertension, family history of CVD and

106 other reproductive factors.

\section{METHODS}

\section{Study participants}

109 InterLACE combines 25 observational, mostly longitudinal cohort studies with data

110 on women's health. A more detailed description of the InterLACE collaboration has

111 been published previously [23, 22]. In brief, participating studies collected

112 retrospective as well as prospective data on key reproductive, sociodemographic,

113 lifestyle and disease outcome variables using self-reported surveys.

114 There were 177750 women who had reported their age at natural menopause and

115 provided information on pre- or post-menopausal CVD events (yes/no) and their age

116 at onset of the CVD event. Because we focused on early premenopausal CVD events,

117 women who experienced premenopausal CVD events after age 50 years (the average

118 age at menopause in this study) were excluded $(n=619)$. The final sample consisted of

119 the 177131 women who had either experienced no premenopausal CVD event (the

120 reference group) or had experienced a premenopausal CVD event before age 50 years,

121 and had complete data on key covariates at baseline including BMI, smoking status,

122 education level, race/ethnicity, and parity. Consequently, nine studies were included

123 in the analyses (Table 1).

\section{Outcome and exposure variables}


125 Age at natural menopause was the outcome variable and was defined as the time when

126 a woman has experienced 12 consecutive months of amenorrhea which was not due to

127 surgery (such as bilateral oophorectomy or hysterectomy). For some women, use of

128 MHT and oral contraceptive pills (OCPs) made it difficult to ascertain their

129 menopausal status; hence MHT or OCP users were excluded unless their age at

130 natural menopause had been reported and the assumption of only post-menopausal

131 MHT use could be made. Age at menopause was categorised as $<45$ (early

132 menopause), 45-49, 50-51 (reference category), 52-53, and 54 years and above (late

133 menopause), according to the clinical recommendation [4] and also as defined in our

134 previous papers $[24,25]$.

135 CVD events were acertained by self-report or/and hospital diagnosis, and were

136 defined as the occurrence of coronary heart disease (CHD, including heart attack and

137 angina) or stroke (including ischemic strokes and haemorrhagic strokes). The

138 exposure variable was the age at onset of premenopausal CVD events, and was

139 categorized as $<35,35-39$, and $\geq 40$ years. We used 35 years as a cut-off point

140 because patients with CVD onset before age 35 years were referred as "very young

141 CVD” and might be genetic predisposed [26, 27]. Also, these CVD events fall into the

142 optimal period of childbearing age $[28,29]$. Women who experienced no

143 premenopausal CVD event were used as the reference group.

\section{Covariates}

145 BMI, smoking status, years of education, race/ethnicity/region, parity and age at

146 menarche collected at baseline were used as covariates. BMI was categorised

147 according to World Health Organization (WHO) criteria as $<18.5 \mathrm{~kg} / \mathrm{m}^{2}, 18.5$ to 24.9

$148 \mathrm{~kg} / \mathrm{m}^{2}, 25$ to $29.9 \mathrm{~kg} / \mathrm{m}^{2}$ and $\geq 30 \mathrm{~kg} / \mathrm{m}^{2}$. Smoking status was categorised as current, 
149 former, or never smokers. Years of education was categorised as follows: $\leq 10,11-12$,

150 and >12 years. Race/ethnicity/region was combined into one with four categories:

151 Caucasian, Asian, African American/Black, and other. Parity was grouped as no

152 children, one child, two, and three or more children. Age at menarche was divided

153 into 5 categories as $\leq 11,12,13,14$, and 15 years or more.

\section{Statistical analysis}

155 We used multinomial (polytomous) logistic regression models to examine the 156 associations between age at onset of premenopausal CVD events and age at natural 157 menopause. CVD events were analysed both as a composite event and for CHD and 158 stroke separately. For the outcome variable, women with an age at menopause of 50-

15951 years were used as the reference group, while for the exposure variable, women 160 who had not experienced premenopausal CVD were the reference group. All models 161 were adjusted for BMI, smoking status, education level, race/ethnicity and parity.

162 Multivariable relative risk ratios (RRR) [30] and 95\% confidence intervals (95\% CI)

163 were used to quantify the association between age at onset of premenopausal CVD 164 events and age at menopause. Because age at menarche is a potential confounder of 165 the CVD-menopause association, it was later included in the model. For this analysis 166 only eight studies were included because age at menarche was not available for the 167 WHITEHALL II study.

168 We conducted several sensitivity analyses to test the robustness of our findings. First, 169 to address the validity of the self-reported CVD events, we only included CVD cases 170 that had a hospital record of diagnosis. Second, because the UK Biobank data 171 contributed more than $50 \%$ of the total premenopausal CVD cases, we conducted an 172 analysis excluding this study to assess its dominance. Third, women who experienced 
173 postmenopausal CVD events may have had unfavourable CVD risk profile before

174 menopause, which might have led to an earlier menopause.[19] Thus, we excluded

175 them from the reference group. Fourth, to guarantee the temporal direction from

176 premenopausal CVD events to menopause, we performed an analysis by only

177 including premenopausal CVD events which occurred at least two years before

178 menopause. Fifth, smoking and BMI are two important factors that may influence age

179 at menopause $[31,24]$. We thus analysed the combined effects of premenopausal

180 CVD events and smoking status, premenopausal CVD events and BMI levels on age

181 at menopause. Sixth, because a previous study had found an association between

182 premenopausal blood pressure and earlier age at menopause [19], we also adjusted for

183 hypertension status before the premenopausal CVD event in the four studies with

184 available information (MCCS, WLH, JNHS, and UK Biobank). Last, we adjusted for

185 family history of CVD using the five studies (MCCS, NHSD, WHITEHALL II, JNHS, 186 and UK Biobank) with relevant information.

187 We used the SURVEYLOGISTIC procedure in SAS software (SAS Version 9.4, SAS

188 Institute Inc, 2008.) with the generalized logit link to adjust for the clustering of data

189 within studies, and to obtain robust standard errors. For all hypothesis tests we used

190 the two-sided 5\% level of significance.

\section{Ethics}

192 Each study in the InterLACE consortium has been undertaken with ethical approval

193 from the Institutional Review Board or Human Research Ethics Committee at each

194 participating institution, and all participants provided consent for that study.

\section{RESULTS}

\section{Study characteristics}


Overall, nine studies (177 131 women) had data on premenopausal CVD events. The majority of women were white $(85.0 \%)$. The mean age (standard deviation, SD) at baseline was 57.8 (7.1) years and ranged from $45.0(3.5)$ to $60.1(9.4)$ years within studies. Over half of the participants were born between 1940 and 1949 (Table 1). There were 1561 women with premenopausal CVD events (including 1130 CHD and 469 stroke). The overall prevalence of premenopausal CVD was $0.9 \%$. The overall mean age at natural menopause was 50.3 (4.4) years and the mean age at first premenopausal CVD event was 41.3(8.2) years (median 44.0 years, interquartile range 38.0-47.0years). The mean age at natural menopause by age categories of premenopausal CVD $<35,35-39$, and $\geq 40$ years were 49.2 (5.3), 49.4 (4.3) and 51.4

(3.3) years respectively. Early age at natural menopause was more common for women with premenopausal CVD events occurring before the age of 35 years than for other groups (Table 2, Figure 1).

\section{Association between premenopausal CVD events and age at menopause}

Compared with women who experienced no premenopausal CVD events, women experiencing a first event before the age of 35 years had around a 2 -fold increased risk of early age ( $<45$ years) at menopause with adjusted RRR $(95 \% \mathrm{CI}) 1.92(1.17,3.14)$ for CVD, $1.86(1.01,3.43)$ for CHD and $2.17(1.43,3.30)$ for stroke. There was a significant increasing trend of the associations between premenopausal CHD $(<35$ years) and earlier age at menopause (P-trend $<0.001)$, while the trend with premenopausal stroke was not significant $(\mathrm{P}$-trend $>0.05)$. Women experiencing first premenopausal CVD events when they were aged more than 35 or 40 years were less likely to experience either earlier (45-49 years) or later age at natural menopause (52 years or more) (Table 3), i.e., they were more likely to experience natural menopause at around 51 years of age (Table 2). For women who experienced premenopausal 
stroke before age 35 years, a statistically significant association was also found with late age at menopause ( $\geq 54$ years) $(1.45,1.10-1.91)$ (Table 3$)$.

\section{Sensitivity analyses}

When only CVD events with a hospital record of diagnosis were included in the analysis, we found results in a similar direction to those from the main analysis.

Nevertheless, the association between premenopausal CHD events ( $<35$ years) and early menopause, and the association between premenopausal stroke $(<35$ years) and late menopause were attenuated and no longer statistically significant (Table 4). Results were also similar when the UK Biobank study was excluded (Table 5) or when women who had experienced a postmenopausal CVD event were excluded from the reference group (Table S1). By including only premenopausal CVD events which occurred at least two years before menopause, similar results were observed (Table S 2). After analysing the combined effect with smoking and BMI, we found the significant associations between CVD events $<35$ years and early menopause were mainly observed in ever smokers and in women who were normal weight (Table S3 and S4). Similar results were also obtained when the analysis was further adjusted for hypertension prior to CVD (Table S5). After the adjustments for family history of CVD, only the association with CVD events was statistically significant, although the point estimates were not changed (Table S6).

\section{DISCUSSION}

Our results show that compared with women who had not experienced any premenopausal CVD event, women experiencing CHD or stroke before age 35 years had twice the risk of having an early menopause ( $<45$ years) rather than a late menopause ( $\geq 54$ years), while women who first experienced premenopausal CVD 
events at age 40 years or older were more likely to have menopause at the average age of 50 to 51years.

\section{The very young premenopausal CVD events}

Coronary atherosclerosis begins at a young age with an estimated prevalence of $28 \%$ under 30 years of age [32]. The prevalence and extent of lesions increases rapidly during the 15 to 34 year age span [33]. Patients with symptomatic CVD onset before 35 years are at times referred as "very young CVD" [26, 27]. Around $1.5 \%$ of all documented CHD cases occur among individuals less than 35 years of age, predominantly in males $[27,34]$. Younger patients have relatively few traditional risk factors such as diabetes mellitus, hypertension, and hyperlipidemia although smoking and family history of CVD have been found to be common [26, 35, 34]. Within the InterLACE consortium the prevalence of family history of CVD was also significantly higher for women with premenopausal CVD events than those without (78\% vs. $60 \%)$ suggesting an inherited genetic predisposition to CVD in young cases.

Mechanisms underlying the link between premenopausal CVD events and age at menopause

Genetics plays an important role in age at natural menopause, with estimates of heritability ranging from $31 \%$ to $87 \%$ [36]. The genetic regions associated with premature or early-onset menopause may also tie to the occurrence of CVD [11]. Thus, our observation of a significant association between "very young CVD" and early menopause may arise due to shared genetic factors. Single nucleotide polymorphisms in several vascular-function-related genes are significantly associated also with age at menopause [36]. The coagulation Factor V Leiden gene, the methylene tetrahydrofolate reductase gene and the Apolipoprotein E gene have all 
270 been linked to earlier age at menopause [37-40], whereas the coagulation factor VII

271 gene is related to delayed menopause [41].

272 An interplay between genetic and environmental factors that may expedite the

273 compromise of vascular health and advance ovarian ageing is also conceivable [37],

274 as well as shared environmental factors. Smoking, for example, is common in those

275 who experience very young CVD events and is also associated with early menopause

$276[26,34,42]$. Smokers carrying single nucleotide polymorphisms CYP3A4*1B and

277 CYP1B $1 * 3$ have a greater risk of menopause commencement compared with those

278 not carrying these variants [43]. Smoking also induces the expression of the

279 apoptosis-promoting gene Bcl2-associated X protein in oocytes leading to an

280 increased rate of oocyte apoptosis, and thus earlier ovarian failure [44].

281 Vascular and ovarian ageing are connected [45]. Coronary disease occurring at a

282 young age may carry a long-term adverse influence on the vasculature [35]. Vascular

283 damage, in turn, may accelerate ovarian ageing and thus lead to early menopause [36,

284 45]. Additionally, fertility often starts declining at age 35 years [28, 29]. Hence, CVD

285 events that occur before age 35 years fall into the optimal period of childbearing age

286 (the average age at onset of premenopausal CVD in those aged $\leq 35$ years' was 27.0

287 years in our study) [29]. It is possible that CVD occurring at optimal reproductive age

288 may affect maternal vascular health in the long term and accelerate the process of

289 reproductive ageing. Although we found no studies evaluating the relationship

290 between damage in large vessels and ovarian ageing, microvascular complications in

291 women with type 1 diabetes have been suggested to accelerate ovarian ageing [46, 26].

292 Our study also found that premenopausal stroke had a stronger association with early

293 menopause than CHD suggesting that a damaged cerebrovascular system is a more 
sensitive marker of ovarian ageing. Further studies are needed to verify this proposition.

Smoking leads to early menopause and overweight/obese has been linked to later menopause $[31,24]$. Our results showed the significant associations between CVD events $<35$ years and early menopause were mainly observed in ever smokers and women with normal weight. In addition, the significant association between premenopausal stroke before age 35 years and late menopause ( $\geq 54$ years) were only observed in women with overweight or obesity, which has been associated with both stroke and late menopause [24].

We also found that women with first CHD or stroke after age 35 years were less likely to experience either earlier (45-49 years) or later natural menopause (52 years or more). The average age at menopause in this group was 51.4 years (Table 2), similar to the mean age at menopause reported in high-income countries [2, 3]. Thus, they were more likely to experience menopause at the 'usual' age. .The median age of premenopausal CVD in this group was 46 years, which means the downstream effect of vascular damage on ovarian ageing is limited. Ovarian ageing in this group to a large extent reflects natural ageing.

\section{Strengths and limitations}

To the best of our knowledge, the link between premenopausal CVD events and timing of menopause has remained untested [47]. The strengths of the current study include participant-level data from nine studies which provided sufficient number of CVD cases to examine in detail the association between premenopausal CVD and the multiple categories of age at menopause. 
Several limitations need also to be acknowledged. First, around $47 \%$ of premenopausal CVD events were self-reported without validation by hospital records. This may have led to some degree of misclassification but findings were reassuringly consistent in the sensitivity analysis that used only hospital ascertained cases. Second, we used the BMI and smoking status values reported at baseline as covariates, which may not reflect their values proximal to the onset of premenopausal CVD. Women with early CVD may have modified their lifestyle resulting in changed BMI and smoking status before menopause. On the other hand, over $50 \%$ of women experienced premenopausal CVD events when aged in their mid-forties or later. For these women, we assume that the misclassification in reported BMI or smoking is limited. For women who had experienced very young CVD ( $<35$ years), their BMI level prior to CVD events might not have been an important risk factor. In two birth cohort studies (NSHD and NCDS) in the InterLACE consortium that also collected BMI and smoking at younger age, the average BMI before 35 years (26-35 years) was 22.4-24.4 kg/m $\mathrm{m}^{2}$, and the concordance in smoking status between age 26 years and baseline age (mid age) was $84 \%$. Third, due to the limited number of cases, we were unable to perform subgroup analysis between sub-types of CHD (angina and heart attack) and age at menopause. Also, most studies did not collect specific types of stroke, so we could not separate the hemorrhagic strokes from ischemic strokes. The associations between different sub-types of stroke with age at menopause may differ due to their dissimilar biological mechanisms. However, approximately $87 \%$ strokes are ischemic [48]. Thus, we believe the bias caused by hemorrhagic strokes was limited. Data that were collected from four countries might have heterogeneity among them. However, after performing country-specific random-effects meta-analysis, we found no significant heterogeneity between studies ( $\mathrm{p}>0.05)$ (data not shown). Last, 
342 because the majority of women were white (Caucasian), our results may need to be

343 verified in other race/ethnicities.

\section{Conclusions}

345 Premenopausal CVD before age 35 years is associated with a higher risk of

346 menopause before age 45 years, while premenopausal CVD after 35 years indicates a

347 normal menopause at around 51 years. Shared genetic and environmental factors

348 (such as smoking), as well as compromised vasculature after CVD events may

349 contribute to this health outcome. Further studies that include measures of vascular

350 damage are needed to examine its possible relationship with age at natural menopause.

351 Additionally, women experiencing a CVD event prior to age 35 years should be

352 alerted for their future high possibility of having early menopause.

\section{Acknowledgments}

354 The data on which this research is based were drawn from 9 observational studies.

355 The research included data from the ALSWH, the University of Newcastle, Australia,

356 and the University of Queensland, Australia. We are grateful to the Australian

357 Government Department of Health for funding and to the women who provided the

358 survey data. MCCS was supported by VicHealth and the Cancer Council, Victoria,

359 Australia. WLHS was funded by a grant from the Swedish Research Council (Grant

360 number 521-2011-2955). NSHD has core funding from the UK Medical Research

361 Council (MC UU 12019/1). NCDS is funded by the Economic and Social Research

362 Council. ELSA is funded by the National Institute on Aging (Grants 2RO1AG7644

363 and 2RO1AG017644-01A1) and a consortium of UK government departments. The

364 Whitehall II study has been supported by grants from the Medical Research Council.

365 Baseline survey of the JNHS was supported in part by a Grant-in-Aid for Scientific 
Research (B: 14370133, 18390195) from the Japan Society for the Promotion of

367 Science, and by the grants from the Japan Menopause Society. This research has been

368 conducted using the UK Biobank resource under application 26629.

369 All studies would like to thank the participants for volunteering their time to be

370 involved in the respective studies. The findings and views in this paper are not

371 necessarily those of the original studies or their respective funding agencies.

372 Author's contribution

373 GDM and DZ conceptualized the study. GDM interpreted the results, and revised the

374 manuscript critically. DZ analysed and interpreted data, and drafted the manuscript.

375 HFC and NP harmonised the data and revised the manuscript. AJD, RH, DK, EJB, FB,

376 GGG, PD, JSL, HM, KH, HOA, EW provided study data and revised the manuscript.

\section{Funding}

378 InterLACE project is funded by the Australian National Health and Medical Research

379 Council project grant (APP1027196). GDM is supported by Australian National

380 Health and Medical Research Council Principal Research Fellowship (APP1121844).

381 The funders had no role in study design, data collection and analysis, decision to

382 publish, or preparation of the manuscript.

\section{Compliance with ethical standards}

384 Conflict of interest

385 The authors declare that they have no conflict of interest. 
1. Harlow SD, Gass M, Hall JE, Lobo R, Maki P, Rebar RW et al. Executive summary of the Stages of Reproductive Aging Workshop+ 10: addressing the unfinished agenda of staging reproductive aging. The Journal of Clinical Endocrinology \& Metabolism. 2012;97(4):1159-68. 2. Morabia A, Costanza MC. International variability in ages at menarche, first livebirth, and menopause. World Health Organization Collaborative Study of Neoplasia and Steroid Contraceptives. Am J Epidemiol. 1998;148(12):1195-205.

3. Gold EB, Crawford SL, Avis NE, Crandall CJ, Matthews KA, Waetjen LE et al. Factors related to age at natural menopause: longitudinal analyses from SWAN. Am J Epidemiol. 2013;178(1):70-83. doi:10.1093/aje/kws421.

4. Shifren JL, Gass ML, NAMS Recommendations for Clinical Care of Midlife Women Working Group. The North American Menopause Society recommendations for clinical care of midlife women. Menopause (New York, NY). 2014;21(10):1038-62. doi:10.1097/GME.0000000000000319.

5. Muka T, Oliver-Williams C, Kunutsor S, Laven JS, Fauser BC, Chowdhury R et al. Association of Age at Onset of Menopause and Time Since Onset of Menopause With Cardiovascular Outcomes, Intermediate Vascular Traits, and All-Cause Mortality: A Systematic Review and Meta-analysis. JAMA Cardiol. 2016;1(7):767-76. doi:10.1001/jamacardio.2016.2415. 6. Lisabeth LD, Beiser AS, Brown DL, Murabito JM, Kelly-Hayes M, Wolf PA. Age at natural menopause and risk of ischemic stroke: the Framingham heart study. Stroke. 2009;40(4):1044-9. doi:10.1161/strokeaha.108.542993.

7. Rocca WA, Grossardt BR, Miller VM, Shuster LT, Brown RD, Jr. Premature menopause or early menopause and risk of ischemic stroke. Menopause (New York, NY). 2012;19(3):272-7. doi:10.1097/gme.0b013e31822a9937.

8. Atsma F, Bartelink ML, Grobbee DE, van der Schouw YT. Postmenopausal status and early menopause as independent risk factors for cardiovascular disease: a meta-analysis. Menopause (New York, NY). 2006;13(2):265-79. doi:10.1097/01.gme.0000218683.97338.ea. 9. Gong D, Sun J, Zhou Y, Zou C, Fan Y. Early age at natural menopause and risk of cardiovascular and all-cause mortality: A meta-analysis of prospective observational studies. International journal of cardiology. 2016;203:115-9. doi:10.1016/j.ijcard.2015.10.092.

10. Matthews KA, Kuller LH, Sutton-Tyrrell K, Chang YF. Changes in cardiovascular risk factors during the perimenopause and postmenopause and carotid artery atherosclerosis in healthy women. Stroke. 2001;32(5):1104-11.

11. McNally E. Reproductive Aging and Cardiovascular Disease Risk. JAMA Cardiol. 2016;1(7):778. doi:10.1001/jamacardio.2016.2638.

12. Woodard GA, Brooks MM, Barinas-Mitchell E, Mackey RH, Matthews KA, Sutton-Tyrrell K. Lipids, menopause, and early atherosclerosis in Study of Women's Health Across the Nation Heart women. Menopause (New York, NY). 2011;18(4):376-84. doi:10.1097/gme.0b013e3181f6480e. 13. Park JK, Lim YH, Kim KS, Kim SG, Kim JH, Lim HG et al. Changes in body fat distribution through menopause increase blood pressure independently of total body fat in middle-aged women: the Korean National Health and Nutrition Examination Survey 2007-2010. Hypertens Res. 2013;36(5):444-9. doi:10.1038/hr.2012.194.

14. Tchernof A, Poehlman ET. Effects of the menopause transition on body fatness and body fat distribution. Obes Res. 1998;6(3):246-54.

15. Son MK, Lim NK, Lim JY, Cho J, Chang Y, Ryu S et al. Difference in blood pressure between early and late menopausal transition was significant in healthy Korean women. BMC Womens Health. 2015;15:64. doi:10.1186/s12905-015-0219-9. 16. Moreau KL, Hildreth KL. Vascular Aging across the Menopause Transition in Healthy Women. Adv Vasc Med. 2014;2014. doi:10.1155/2014/204390. 
17. Hardy R, Lawlor DA, Kuh D. A life course approach to cardiovascular aging. Future Cardiol. 2015;11(1):101-13. doi:10.2217/fca.14.67.

18. Writing Group for the Women's Health Initiative Investigators. Risks and benefits of estrogen plus progestin in healthy postmenopausal women: principal results from the Women's Health Initiative randomized controlled trial. Jama. 2002;288(3):321-33.

19. Kok HS, van Asselt KM, van der Schouw YT, van der Tweel I, Peeters PH, Wilson PW et al. Heart disease risk determines menopausal age rather than the reverse. J Am Coll Cardiol. 2006;47(10):1976-83. doi:10.1016/j.jacc.2005.12.066.

20. Bittner V. Menopause and cardiovascular risk cause or consequence? J Am Coll Cardiol. 2006;47(10):1984-6. doi:10.1016/j.jacc.2006.02.032.

21. Wellons M, Ouyang P, Schreiner PJ, Herrington DM, Vaidya D. Early menopause predicts future coronary heart disease and stroke: the Multi-Ethnic Study of Atherosclerosis. Menopause (New York, NY). 2012;19(10):1081-7. doi:10.1097/gme.0b013e3182517bd0. 22. Mishra GD, Anderson D, Schoenaker DA, Adami H-O, Avis NE, Brown D et al. InterLACE: a new international collaboration for a life course approach to women's reproductive health and chronic disease events. Maturitas. 2013;74(3):235-40.

23. Mishra GD, Chung H-F, Pandeya N, Dobson AJ, Jones L, Avis NE et al. The InterLACE study: Design, data harmonization and characteristics across 20 studies on women's health. Maturitas. 2016;92:176-85.

24. Zhu D, Chung HF, Pandeya N, Dobson AJ, Kuh D, Crawford SL et al. Body mass index and age at natural menopause: an international pooled analysis of 11 prospective studies. Eur J Epidemiol. 2018;33(8):699-710. doi:10.1007/s10654-018-0367-y.

25. Mishra GD, Pandeya N, Dobson AJ, Chung HF, Anderson D, Kuh D et al. Early menarche, nulliparity and the risk for premature and early natural menopause. Hum Reprod. 2017. doi:10.1093/humrep/dew350.

26. Christus T, Shukkur AM, Rashdan I, Koshy T, Alanbaei M, Zubaid M et al. Coronary Artery Disease in Patients Aged 35 or less - A Different Beast? Heart Views. 2011;12(1):7-11. doi:10.4103/1995-705X.81550.

27. Wolfe MW, Vacek JL. Myocardial infarction in the young. Angiographic features and risk factor analysis of patients with myocardial infarction at or before the age of 35 years. Chest. 1988;94(5):926-30.

28. Medicine PCotASfR. Age-related fertility decline: a committee opinion. Fertility and sterility. 2008;90(5):S154-S5.

29. Te Velde E, Dorland M, Broekmans F. Age at menopause as a marker of reproductive ageing. Maturitas. 1998;30(2):119-25.

30. Borooah VK. Logit and probit: Ordered and multinomial models. vol 138. Sage; 2002. 31. Zhu D, Chung HF, Pandeya N, Dobson AJ, Cade JE, Greenwood DC et al. Relationships between intensity, duration, cumulative dose, and timing of smoking with age at menopause: A pooled analysis of individual data from 17 observational studies. PLoS Med. 2018;15(11):e1002704. doi:10.1371/journal.pmed.1002704.

32. Tuzcu EM, Kapadia SR, Tutar E, Ziada KM, Hobbs RE, McCarthy PM et al. High prevalence of coronary atherosclerosis in asymptomatic teenagers and young adults: evidence from intravascular ultrasound. Circulation. 2001;103(22):2705-10.

33. Strong JP, Malcom GT, McMahan CA, Tracy RE, Newman WP, 3rd, Herderick EE et al. Prevalence and extent of atherosclerosis in adolescents and young adults: implications for prevention from the Pathobiological Determinants of Atherosclerosis in Youth Study. JAMA. 1999;281(8):727-35.

34. Kalimuddin M, Ahmed N, Badiuzzzaman M, Ahmed MN, Dutta A, Banik D et al. AMI in very young (aged $\leqslant 35$ years) Bangladeshi patients: Risk factors \& coronary angiographic profile. Clinical Trials and Regulatory Science in Cardiology. 2016;13:1-5. 
35. Cole JH, Miller JI, 3rd, Sperling LS, Weintraub WS. Long-term follow-up of coronary artery disease presenting in young adults. J Am Coll Cardiol. 2003;41(4):521-8. 36. Voorhuis M, Onland-Moret NC, van der Schouw YT, Fauser BC, Broekmans FJ. Human studies on genetics of the age at natural menopause: a systematic review. Hum Reprod Update. 2010;16(4):364-77. doi:10.1093/humupd/dmp055.

37. van Asselt KM, Kok HS, Peeters PH, Roest M, Pearson PL, te Velde ER et al. Factor V Leiden mutation accelerates the onset of natural menopause. Menopause (New York, NY). 2003;10(5):477-81. doi:10.1097/01.GME.0000056040.51813.1A. 38. Tempfer CB, Riener EK, Keck C, Grimm C, Heinze G, Huber JC et al. Polymorphisms associated with thrombophilia and vascular homeostasis and the timing of menarche and menopause in 728 white women. Menopause (New York, NY). 2005;12(3):325-30. 39. Liu P, Lu Y, Recker RR, Deng HW, Dvornyk V. Association analyses suggest multiple interaction effects of the methylenetetrahydrofolate reductase polymorphisms on timing of menarche and natural menopause in white women. Menopause (New York, NY). 2010;17(1):185-90. doi:10.1097/gme.0b013e3181aa2597. 40. He LN, Recker RR, Deng HW, Dvornyk V. A polymorphism of apolipoprotein E (APOE) gene is associated with age at natural menopause in Caucasian females. Maturitas. 2009;62(1):37-41. doi:10.1016/j.maturitas.2008.10.011.

41. van Disseldorp J, Broekmans FJ, Peeters PH, Fauser BC, van der Schouw YT. The association between vascular function-related genes and age at natural menopause. Menopause (New York, NY). 2008;15(3):511-6. doi:10.1097/gme.0b013e31814cec52. 42. Parente RC, Faerstein E, Celeste RK, Werneck GL. The relationship between smoking and age at the menopause: A systematic review. Maturitas. 2008;61(4):287-98. doi:10.1016/j.maturitas.2008.09.021. 43. Butts SF, Sammel MD, Greer C, Rebbeck TR, Boorman DW, Freeman EW. Cigarettes, genetic background, and menopausal timing: the presence of single nucleotide polymorphisms in cytochrome $\mathrm{P} 450$ genes is associated with increased risk of natural menopause in European-American smokers. Menopause (New York, NY). 2014;21(7):694701. doi:10.1097/GME.0000000000000140.

44. Dechanet C, Anahory T, Mathieu Daude JC, Quantin X, Reyftmann L, Hamamah S et al. Effects of cigarette smoking on reproduction. Hum Reprod Update. 2011;17(1):76-95. doi:10.1093/humupd/dmq033.

45. Yarde F. Advanced Ovarian Ageing: Studies on Fertility and Vascular Health: Utrecht University; 2014.

46. Sjoberg L, Pitkaniemi J, Harjutsalo V, Haapala L, Tiitinen A, Tuomilehto J et al. Menopause in women with type 1 diabetes. Menopause (New York, NY). 2011;18(2):158-63. doi:10.1097/gme.0b013e3181ef3af0.

47. Manson JE, Woodruff TK. Reproductive Health as a Marker of Subsequent Cardiovascular Disease: The Role of Estrogen. JAMA Cardiol. 2016;1(7):776-7. doi:10.1001/jamacardio.2016.2662.

48. Rosamond W, Flegal K, Furie K, Go A, Greenlund K, Haase N et al. Heart disease and stroke statistics--2008 update: a report from the American Heart Association Statistics Committee and Stroke Statistics Subcommittee. Circulation. 2008;117(4):e25-146. doi:10.1161/CIRCULATIONAHA.107.187998. 
Table 1. Characteristics of women in each study of the InterLACE consortium ${ }^{\text {a }}$

\begin{tabular}{|c|c|c|c|c|c|c|c|c|c|}
\hline \multirow[b]{2}{*}{ Study } & \multirow[b]{2}{*}{ Country } & \multirow[b]{2}{*}{$\mathrm{N}$} & \multirow{2}{*}{$\begin{array}{l}\text { Age at baseline, } \\
\text { Mean (SD) }\end{array}$} & \multirow{2}{*}{$\begin{array}{l}\text { Age at last follow- } \\
\text { up, Mean (SD) }\end{array}$} & \multicolumn{5}{|c|}{ Women's year of birth (\%) } \\
\hline & & & & & $<1930$ & $\begin{array}{c}1930- \\
1939\end{array}$ & $\begin{array}{l}1940- \\
1949\end{array}$ & $\begin{array}{l}1950- \\
1959\end{array}$ & $1960+$ \\
\hline $\begin{array}{l}\text { Australian Longitudinal Study on Women's Health } \\
\text { (ALSWH) }\end{array}$ & Australia & 7061 & $47.6(1.4)$ & $63.2(3.3)$ & . & . & 74.8 & 25.2 & . \\
\hline Melbourne Collaborative Cohort Study (MCCS) & Australia & 12814 & $58.7(7.2)$ & $67.9(7.6)$ & 35.6 & 42.6 & 19.8 & 2.0 & . \\
\hline Women's Lifestyle and Health Study (WLHS) & Sweden & 10659 & $45.0(3.5)$ & $55.8(3.7)$ & . & . & 77.0 & 22.7 & 0.3 \\
\hline MRC National Survey of Health and Development (NSHD) ${ }^{b}$ & UK & 631 & 47.0 & 53.9 & . & . & 100 & . & . \\
\hline National Child Development Study (NCDS) ${ }^{b}$ & UK & 2407 & 50.0 & 54.8 & . & . & . & 100 & . \\
\hline English Longitudinal Study of Ageing (ELSA) & UK & 3595 & $60.1(9.4)$ & $68.7(9.8)$ & 16.4 & 25.6 & 35.8 & 22.1 & 0.2 \\
\hline Whitehall II study (WHITEHALL II) & UK & 1460 & $46.0(5.8)$ & $64.8(5.9)$ & . & 46.4 & 46.8 & 6.7 & . \\
\hline Japan Nurse's Health Study (JNHS) & Japan & 4933 & $54.7(3.9)$ & $54.7(3.9)$ & . & 1.5 & 63.6 & 34.2 & 0.7 \\
\hline UK Biobank (UK Biobank) & UK & 133571 & $59.6(5.6)$ & $60.1(5.5)$ & . & 4.0 & 55.4 & 37.5 & 3.0 \\
\hline All & & 177131 & $57.8(7.1)$ & $60.5(6.3)$ & 2.9 & 7.1 & 54.1 & 33.6 & 2.3 \\
\hline
\end{tabular}

${ }^{\mathrm{a}}$ In this study, the dataset included women who experienced premenopausal CVD events (including CHD and stroke) and had reported their age at onset of CVD events, and women who had no premenopausal CVD event (used as reference group). All women had complete information on age at natural menopause and key covariates.

${ }^{b}$ NSHD (1946 British Birth Cohort) and NCDS (1958 British Birth Cohort) first collected information on women's health in 1993 (aged 47 ) and 2008 (aged 50), respectively, so we used 1993 and 2008 as the baseline year for the InterLACE.

Abbreviations: InterLACE, International Collaboration for a Life Course Approach to Reproductive Health and Chronic Disease Events; SD, standard deviation; CVD, cardiovascular disease; CHD, coronary heart disease. 
Table 2. Average age at onset of premenopausal CVD events, average age and distribution of natural menopause by age categories of premenopausal CVD/CHD/stroke events

\begin{tabular}{|c|c|c|c|c|c|c|c|c|c|}
\hline & \multirow{2}{*}{$\begin{array}{c}\text { Number of } \\
\text { premenopausal } \\
\text { CVD/CHD/stro } \\
\text { ke events } \\
\end{array}$} & \multicolumn{2}{|c|}{$\begin{array}{c}\text { Age at premenopausal } \\
\text { CVD/CHD/stroke event }\end{array}$} & \multirow{2}{*}{$\begin{array}{l}\text { Age at natural } \\
\text { menopause, } \\
\text { Mean (SD) }\end{array}$} & \multicolumn{5}{|c|}{ Distribution of age at natural menopause } \\
\hline & & $\begin{array}{l}\text { Mean } \\
(\mathrm{SD})\end{array}$ & $\begin{array}{c}\text { Median } \\
(\mathrm{Q} 1, \mathrm{Q} 3)\end{array}$ & & $<45$ & $45-49$ & $50-51$ & $52-53$ & $\geq 54$ \\
\hline \multicolumn{10}{|l|}{$\begin{array}{l}\text { Age at onset of premenopausal } \\
\text { CVD events }\end{array}$} \\
\hline$<35$ & 287 & $27.0(7.4)$ & $29.4(23.0,33.0)$ & $49.2(5.3)$ & $46(16.0)$ & $82(28.6)$ & $59(20.6)$ & $45(15.7)$ & $55(19.2)$ \\
\hline $35-39$ & 151 & $37.1(1.4)$ & $37.0(36.0,38.0)$ & $49.4(4.3)$ & $16(10.6)$ & $45(29.8)$ & $45(29.8)$ & $23(15.2)$ & $22(14.6)$ \\
\hline$\geq 40$ & 1123 & $45.5(2.9)$ & $46.0(43.0,48.0)$ & $51.4(3.3)$ & $17(1.5)$ & $240(21.4)$ & $358(31.9)$ & $240(21.4)$ & $268(23.9)$ \\
\hline No premenopausal CVD event & - & - & - & $50.3(4.4)$ & $16029(9.1)$ & $42803(24.4)$ & $42829(24.4)$ & $34766(19.8)$ & $39143(22.3)$ \\
\hline \multicolumn{10}{|l|}{$\begin{array}{l}\text { Age at onset of premenopausal } \\
\text { CHD events }\end{array}$} \\
\hline$<35$ & 185 & $27.2(8.0)$ & $31.0(24.0,33.0)$ & $48.9(5.0)$ & $29(15.7)$ & $56(30.3)$ & $38(20.5)$ & $34(18.4)$ & $28(15.1)$ \\
\hline$\geq 35$ & 945 & $44.7(3.7)$ & $45.0(42.0,48.0)$ & $51.3(3.4)$ & $21(2.2)$ & $207(21.9)$ & $300(31.7)$ & $191(20.2)$ & $226(23.9)$ \\
\hline No premenopausal CHD event & - & - & - & $50.3(4.4)$ & $16037(9.1)$ & $42863(24.4)$ & $42929(24.4)$ & $34839(19.8)$ & $39301(22.3)$ \\
\hline \multicolumn{10}{|l|}{$\begin{array}{l}\text { Age at onset of premenopausal } \\
\text { stroke }\end{array}$} \\
\hline$<35$ & 114 & $27.5(6.5)$ & $28.0(24.0,32.0)$ & $49.6(5.7)$ & $19(16.7)$ & $28(24.6)$ & $22(19.3)$ & $15(13.2)$ & $30(26.3)$ \\
\hline$\geq 35$ & 355 & $44.2(3.9)$ & $45.0(41.0,48.0)$ & $50.8(3.4)$ & $13(3.7)$ & $87(24.5)$ & $112(31.5)$ & $76(21.4)$ & $67(18.9)$ \\
\hline No premenopausal stroke & - & - & - & $50.4(4.4)$ & $15819(9.1)$ & $42152(24.1)$ & $42687(24.5)$ & 34434 (19.7) & $39486(22.6)$ \\
\hline
\end{tabular}

Abbreviations: CVD, cardiovascular disease; CHD, coronary heart disease; SD, standard deviation.

2

3

4 
Table 3. Unadjusted and adjusted associations between age at premenopausal CVD/CHD/stroke events and age at natural menopause ${ }^{\mathrm{a}}(\mathrm{n}=177 \mathrm{131})$

\begin{tabular}{|c|c|c|c|c|c|c|c|c|}
\hline & \multicolumn{4}{|c|}{ Age at natural menopause: crude RRRs ( $95 \%$ CI) } & \multicolumn{4}{|c|}{ Age at natural menopause: adjusted RRRs $(95 \% \mathrm{CI})^{\mathrm{b}}$} \\
\hline & $<45$ & $45-49$ & $52-53$ & $\geq 54$ & $<45$ & $45-49$ & $52-53$ & $\geq 54$ \\
\hline \multicolumn{9}{|l|}{$\begin{array}{l}\text { Age at onset of premenopausal } \\
\text { CVD events }\end{array}$} \\
\hline$<35$ & $2.07(1.29,3.31)$ & $1.36(0.94,1.96)$ & $0.94(0.69,1.27)$ & $1.05(0.77,1.52)$ & $1.92(1.17,3.14)$ & $1.30(0.91,1.85)$ & $0.94(0.70,1.27)$ & $1.05(0.79,1.41)$ \\
\hline $35-39$ & $0.95(0.69,1.29)$ & $0.99(0.72,1.35)$ & $0.63(0.50,0.80)$ & $0.54(0.38,0.76)$ & $0.88(0.65,1.19)$ & $0.95(0.71,1.29)$ & $0.64(0.50,0.81)$ & $0.54(0.37,0.79)$ \\
\hline$\geq 40^{\mathrm{c}}$ & - & $0.66(0.54,0.80)$ & $0.82(0.69,0.98)$ & $0.84(0.71,1.00)$ & & $0.62(0.51,0.75)$ & $0.84(0.71,0.99)$ & $0.85(0.72,0.99)$ \\
\hline $\begin{array}{l}\quad \text { No premenopausal CVD } \\
\text { event } \\
\text { Age at onset of premenopausal } \\
\text { CHD events }\end{array}$ & 1.00 & 1.00 & 1.00 & 1.00 & 1.00 & 1.00 & 1.00 & 1.00 \\
\hline$<35$ & $2.02(1.14,3.59)$ & $1.43(0.85,2.39)$ & $1.10(0.85,1.43)$ & $0.83(0.48,1.45)$ & $1.86(1.01,3.43)$ & $1.34(0.80,2.23)$ & $1.10(0.84,1.45)$ & $0.86(0.50,1.47)$ \\
\hline$\geq 35^{\mathrm{c}}$ & - & $0.67(0.50,0.91)$ & $0.78(0.65,0.94)$ & $0.84(0.69,1.04)$ & & $0.64(0.47,0.86)$ & $0.80(0.67,0.95)$ & $0.85(0.72,1.01)$ \\
\hline $\begin{array}{l}\quad \text { No premenopausal CHD } \\
\text { event } \\
\text { Age at onset of premenopausal } \\
\text { stroke }\end{array}$ & 1.00 & 1.00 & 1.00 & 1.00 & 1.00 & 1.00 & 1.00 & 1.00 \\
\hline$<35$ & $2.33(1.53,3.54)$ & $1.29(0.86,1.93)$ & $0.85(0.54,1.33)$ & $1.48(1.13,1.93)$ & $2.17(1.43,3.30)$ & $1.26(0.84,1.90)$ & $0.85(0.55,1.33)$ & $1.45(1.10,1.91)$ \\
\hline$\geq 35^{\mathrm{c}}$ & - & $0.78(0.64,0.95)$ & $0.84(0.70,1.01)$ & $0.65(0.57,0.74)$ & & $0.74(0.60,0.93)$ & $0.85(0.71,1.02)$ & $0.65(0.57,0.74)$ \\
\hline No premenopausal stroke & 1.00 & 1.00 & 1.00 & 1.00 & 1.00 & 1.00 & 1.00 & 1.00 \\
\hline
\end{tabular}

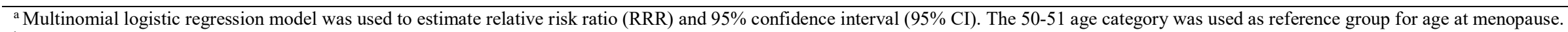
${ }^{\mathrm{b}}$ Body mass index, smoking status, years of education, race/ethnicity/region, number of children at baseline were adjusted.

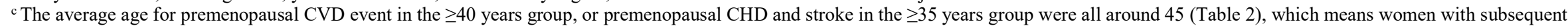
early menopause were less likely to be included in these groups. So we use a "-" to represent their effect on early menopause. 
Table 4 . The associations between age at premenopausal CVD/CHD/stroke events and age at natural menopause--Only cases with hospital diagnosed record were included ${ }^{\text {a }}(\mathrm{n}=176265)$

\begin{tabular}{|c|c|c|c|c|c|c|c|c|c|}
\hline & \multicolumn{5}{|c|}{ Age at menopause, n (\%) } & \multicolumn{4}{|c|}{ Adjusted RRRs $(95 \% \mathrm{CI})^{\mathrm{b}}$} \\
\hline & $<45$ & $45-49$ & $50-51$ & $52-53$ & $>=54$ & $<45^{\mathrm{c}}$ & $45-49$ & $52-53$ & $>=54$ \\
\hline \multicolumn{10}{|c|}{$\begin{array}{l}\text { Age of onset of } \\
\text { premenopausal CVD events }\end{array}$} \\
\hline$<35$ & $18(17.0)$ & $28(26.4)$ & 24 (22.6) & $14(13.2)$ & $22(20.8)$ & $1.73(1.02,3.00)$ & $1.11(0.88,1.40)$ & $0.73(0.47,1.15)$ & $0.98(0.89,1.08)$ \\
\hline$\geq 35$ & $19(3.2)$ & $145(24.6)$ & $172(29.2)$ & $123(20.9)$ & $130(22.1)$ & & $0.80(0.68,0.94)$ & $0.89(0.71,1.11)$ & $0.80(0.70,0.91)$ \\
\hline $\begin{array}{l}\quad \text { No premenopausal } \\
\text { CVD event } \\
\text { Age of onset of } \\
\text { premenopausal CHD eve }\end{array}$ & $16029(9.1)$ & $42803(24.4)$ & $42829(24.4)$ & $34766(19.8)$ & $39143(22.3)$ & 1.00 & 1.00 & 1.00 & 1.00 \\
\hline$<35$ & $10(16.1)$ & $18(29.0)$ & $15(24.2)$ & $10(16.1)$ & $9(14.5)$ & $1.53(0.65,3.61)$ & $1.15(0.69,1.89)$ & $0.84(0.47,1.52)$ & $0.65(0.48,0.88)$ \\
\hline$\geq 35$ & $15(3.3)$ & $103(22.5)$ & 131 (28.6) & $96(21.0)$ & $113(24.7)$ & & $0.75(0.61,0.92)$ & $0.91(0.72,1.16)$ & $0.90(0.79,1.02)$ \\
\hline $\begin{array}{l}\text { No premenopausal } \\
\text { CHD event } \\
\text { Age of onset of } \\
\text { premenopausal stroke }\end{array}$ & $16037(9.1)$ & $42863(24.4)$ & 42929 (24.4) & 34839 (19.8) & $39301(22.3)$ & 1.00 & 1.00 & 1.00 & 1.00 \\
\hline$<35$ & $9(21.4)$ & $10(23.8)$ & $9(21.4)$ & $4(9.5)$ & $10(23.8)$ & $2.37(1.53,3.70)$ & $1.09(0.42,2.80)$ & $0.56(0.25,1.27)$ & $1.17(0.60,2.30)$ \\
\hline$\geq 35$ & $5(3.7)$ & $42(30.9)$ & $41(30.1)$ & $29(21.3)$ & $19(14.0)$ & & $0.98(0.73,1.31)$ & $0.88(0.64,1.22)$ & $0.50(0.30,0.80)$ \\
\hline $\begin{array}{l}\text { No premenopausal } \\
\text { stroke }\end{array}$ & $15819(9.1)$ & $42152(24.1)$ & $42687(24.5)$ & 34434 (19.7) & $39486(22.6)$ & 1.00 & 1.00 & 1.00 & 1.00 \\
\hline
\end{tabular}

$15819(9.1) \quad 42152(24.1) \quad 42687(24.5) \quad 34434(19.7) \quad 39486(22.6)$

1.00

${ }^{a}$ Multinomial logistic regression model was used to estimate relative risk ratio (RRR) and $95 \%$ confidence interval $(95 \% \mathrm{C})$.
${ }^{\mathrm{b}}$ Body mass index, smoking status, years of education, race/ethnicity/region, number of children at baseline were adjusted.

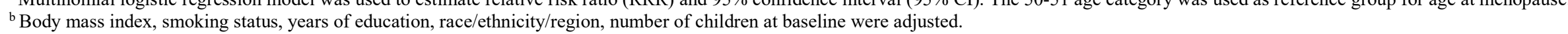

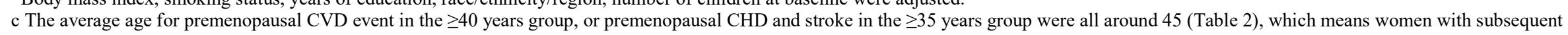
early menopause were less likely to be included in these groups. So we use a "-" to represent their effect on early menopause.

Abbreviations: CVD, cardiovascular disease; CHD, coronary heart disease.

2 
Table 5. The associations between age at premenopausal CVD/CHD/stroke events and age at natural menopause-After excluding UK Biobank study ${ }^{a}$

\begin{tabular}{|c|c|c|c|c|c|c|c|c|c|}
\hline & \multicolumn{5}{|c|}{ Age at menopause, n (\%) } & \multicolumn{4}{|c|}{ Adjusted RRRs $(95 \% \mathrm{CI})^{\mathrm{b}}$} \\
\hline & $<45$ & $45-49$ & $50-51$ & $52-53$ & $>=54$ & $<45^{\mathrm{c}}$ & $45-49$ & $52-53$ & $>=54$ \\
\hline \multicolumn{10}{|l|}{$\begin{array}{l}\text { Age of onset of } \\
\text { premenopausal CVD events }\end{array}$} \\
\hline$<35$ & $29(19.3)$ & $49(32.7)$ & $26(17.3)$ & $25(16.7)$ & $21(14.0)$ & $2.82(1.71,4.63)$ & $1.67(1.19,2.35)$ & $1.17(0.76,1.81)$ & $1.08(0.55,2.10)$ \\
\hline$\geq 35$ & $12(2.1)$ & $126(21.7)$ & $202(34.8)$ & $115(19.8)$ & $126(21.7)$ & - & $0.56(0.45,0.69)$ & $0.71(0.58,0.87)$ & $0.82(0.59,1.12)$ \\
\hline \multicolumn{10}{|l|}{$\begin{array}{l}\text { Age of onset of } \\
\text { premenopausal CHD events }\end{array}$} \\
\hline$<35$ & $22(18.2)$ & $42(34.7)$ & $21(17.4)$ & $20(16.5)$ & $16(13.2)$ & $2.65(1.48,4.74)$ & $1.76(1.22,2.55)$ & $1.16(0.70,1.94)$ & $1.05(0.44,2.52)$ \\
\hline$\geq 35$ & $9(1.8)$ & $99(20.3)$ & $174(35.7)$ & 97 (19.9) & $109(22.3)$ & - & $0.50(0.41,0.63)$ & $0.70(0.59,0.83)$ & $0.83(0.61,1.13)$ \\
\hline \multicolumn{10}{|l|}{$\begin{array}{l}\text { Age of onset of } \\
\text { premenopausal stroke }\end{array}$} \\
\hline$<35$ & $8(26.7)$ & $6(20.0)$ & $6(20.0)$ & $4(13.3)$ & $6(20.0)$ & $3.42(1.07,10.9)$ & $0.95(0.25,3.55)$ & $0.86(0.16,4.44)$ & $1.20(0.52,2.74)$ \\
\hline$\geq 35$ & $3(2.6)$ & $34(29.8)$ & $36(31.6)$ & $21(18.4)$ & $20(17.5)$ & - & $0.89(0.55,1.42)$ & $0.73(0.44,1.24)$ & $0.65(0.44,0.96)$ \\
\hline $\begin{array}{l}\text { No premenopausal } \\
\text { stroke }\end{array}$ & 3651 (8.9) & $10787(26.2)$ & $10329(25.1)$ & 8113 (19.7) & $8266(20.1)$ & 1.00 & 1.00 & 1.00 & 1.00 \\
\hline \multicolumn{10}{|c|}{$\begin{array}{l}{ }^{a} \text { Multinomial logistic regression model was used to estimate relative risk ratio (RRR) and } 95 \% \text { confidence interval ( } 95 \% \text { CI). The } 50-51 \text { age category was used as reference group for age at menopause. } \\
{ }^{\mathrm{b}} \text { Body mass index, smoking status, years of education, race/ethnicity/region, number of children, age at menarche at baseline. } \\
{ }^{\mathrm{c}} \text { The average age for premenopausal CVD event in the } \geq 40 \text { years group, or premenopausal CHD and stroke in the } \geq 35 \text { years group were all around } 45 \text { (Table } 2 \text { ), which means women with subsequent } \\
\text { early menopause were less likely to be included in these groups. So we use a “-" to represent their effect on early menopause. } \\
\text { Abbreviations: CVD, cardiovascular disease; CHD, coronary heart disease. }\end{array}$} \\
\hline 2 & & & & & & & & & \\
\hline 3 & & & & & & & & & \\
\hline 4 & & & & & & & & & \\
\hline & & & & & & & & & \\
\hline
\end{tabular}




\section{$1 \quad$ Figure legends}

2 Fig. 1 Distribution of age at menopause in different age categories of premenopausal

$3 \mathrm{CVD} / \mathrm{CHD} /$ stroke events. Abbreviations: CVD, cardiovascular disease; $\mathrm{CHD}$, coronary heart 4 disease. 